\section{Objects of the Universe}

\section{David W. Hughes}

Catalogue of the Universe. By Paul Murdin and David Allen, with photographs by David Malin. Pp.256. (Cambridge University Press: Cambridge, 1979.) £9.50.

cătálǒguje, n. a list or enumeration systematically arranged in alphabetical or other order, often with the addition of brief particulars.

ūn'ivêrse, $\mathbf{n}$. The whole of created or existing things regarded collectively; all things, including the earth, the heavens, and all that is in them, considered as constituting a systematic whole.

ON reading these two dictionary entries the enormity of the task the authors had set themselves seemed overwhelming. Murdin, Allen and Malin have, however, assembled a much simplified catalogue of astronomical objects and planetary features. The book is a picture gallery of galaxies, stars, nebulae and planets, each photograph being accompanied, on average, by an equal area of prose. The balance is reasonable too: $26 \%$ galaxies, $36 \%$ stars and nebulae, and $38 \%$ planets.

In the preface the authors state that the photographs are the core of the book, and a "best-buy" policy has been adopted in selecting the ones for inclusion. They then bravely go on to say: "We hope that an astronomer browsing in the sections which lie outside his special field thinks that the best-buy choices are justified, even if he happens to disagree with us in the area he knows about." Well I did just that and obviously this makes me very worried. My field is the Solar System, especially the minor bodies in it comets, asteroids, meteorites and meteoroids. The photographs in this section were poor - I'm sure I could have selected much better ones myself. Also having NASA slides in my collection of many of the Moon, Mercury and Mars photographs used in the book, underlined the fact that many of the reproductions in these sections are not of the best. However, as I wandered away from my field and browsed in other pastures I became more and more impressed. The Lagoon nebula looked sharper than I had ever seen it before, thanks to some of the special photographic techniques used for the illustrations. On the other hand, even here a common illustration like the Lund Observatory's composite photograph of the Milky Way has been so badly reproduced that much of the detail you know exists on the original is invisible, But I'm still worried about the author's admonition. May be if I meet an expert of that speciality in some distant pasture, wouldn't he be as disillusioned with his area as I was with mine? It's quite surprising isn't it how impressive certain books can be when they discuss things you haven't encountered before, only to become painfully weak when they turn to your own speciality.

The text also worries me. Common catalogues like stamp catalogues and horticultural catalogues at least tell you how big the stamps are, their perforation, the issue dates and print numbers; and when reading about the plants I expect to learn how tall and hardy they are or whether they like shade or sun. Common catalogues abound with quantitative details. Not so this one. Time and again I get the impression the reader is being talked down to. I want to know how rare, hot, massive, dense, luminous, old (etcetera, etcetera) these objects are, I'm not told often enough. If I've gone to the trouble of looking up "infrared radiation" in the glossary I want to be told more than that it is just heatwaves. Any author who writes that fireball trains are nearly as wide as the Full Moon sows seeds of doubt in my mind about his other prognostications.

The underlying, motivating, idea behind the book is extremely good. A catalogue of the objects of the Universe, well illustrated with a concise factual test would be most useful. Unfortunately with this book both the illustrations and the text let it down. Remove these and there is little to say other than that it has a pretty cover.

David $W$. Hughes is Lecturer in the Department of Physics and Astronomy at the University of Sheffield, $U K$.

\section{Physical optics}

\section{P.W. Hawkes}

Optical Image Formation and Processing. By M. Françon. Pp. 213. (Academic: New York, San Francisco and London, 1979.) $\$ 19.50 ; £ 12.80$.

THE past twenty years have seen a number of major developments in optics, but for the newcomer, their relative novelty simply means that older textbooks will not cover them and that some of the newer ones, or new editions of the old, will treat them as difficult advanced topics or in brief, alltoo-often obscure appendices. Professor Françon is too experienced a teacher of optics to fall into either of these traps. He has written a short introductory text on physical optics, in which such topics as partial coherence, transfer functions, holography, speckle interferometry, image processing, lasers and optical waveguides are treated alongside and in exactly the same tone of voice as, for example, Babinet's principle and the Michelson interferometer. Students encountering physical optics for the first time will find the style clear and the mathematics simple and easy to follow. Only in one case did I find the clarity deceptive, namely, the treatment of speckle; here, I feel that the newcomer will find himself following the discussion effortlessly but without the least idea of what speckle is all about.

In a book intended for beginners, the quality of the translation is particularly important. The translator, B.M. Jaffé, has produced a text that is smooth and lucid for the most part, though here and there a technical phrase has eluded him. The only one that matters is "pattern recognition", for which B.M. Jaffé writes "form recognition" (from reconnaissance des formes). From personal experience, I know how easy it is to be hypnotised into translating into perfectly grammatical but somewhat unnatural English and B.M. Jaffé is occasionally, though not often, guilty of this: "If one agrees to allow the frequency to vary..." (p 59), for example, and " . . . it will be necessary to remind the reader of the basic properties ... " (p 98). Here and there, I felt he might have inserted (if the author agreed) a helpful phrase; thus again on $\mathrm{p} 98$ it would have been useful to mention that fig. 8.1 is commonly known as the HurterDriffield or H-D curve and to put " $\log$ W" in the text. On p 190, he really ought to have noticed that, although "The first of the two relations (A.28) is often given the name of Parseval's theorem"', this is in fact wrong and Parseval's theorem states something different, which is easily derived from the relation in question.

Nevertheless, these are only very minor blemishes in a book that first or secondyear undergraduates, revising for exams, will find immensely helpful particularly if Academic Press produce a paperback that they can afford.

P.W. Hawkes is Maître de Recherches in the Laboratoire d'Optique Electronique du CNRS, Toulouse, France. 